of the programme during 1953, the third financial period. It also includes information on the approved programme for 1954 and some details on that proposed for 1955. Almost 200 out of the 267 pages of the report are occupied by the statements of the participating organizations and an analytical summary of the programmes for 1953-55 taken country by country. The general features of the Expanded Programme are discussed in an introduction which is illustrated by a series of diagrams and charts ; and, in view of what has already been recently published in Nature $(173,50$ and 174,$1 ; 1954)$, it is unnecessary here to refer to more than a few points.

In the four years since the Programme began, the less-developed countries have re-examined their economic and social problems and have invited many thousands of experts from many lands to work with and for them. The technical skill and experience of many countries have been drawn upon to accelerate progress where it has lagged, and the report claims that in some measure the energies and initiative, the hopes and capacity for self-help of many peoples have been quickened. Nevertheless, the volume of technical assistance fell slightly, from $22,968,129$ dollars in 1952 to $22,810,000$ dollars, partly in consequence of a thorough review of the Programme, when pledges for 1953 , totalling 22.4 million dollars, fell far below the cost of the technical assistance requested. The number of countries and territories receiving experts, however, increased from sixty-two to sixty-five, although fellowships were awarded to nationals of only eighty-two countries, compared with ninety-two in 1952, and sixty-seven, as compared with seventy-six, countries or territories acted as hosts to Fellows.

Attempting to distinguish features of the Programme on the basis of five years of operation, the report points out that only a small proportion of the funds is required to meet urgent priority requests : most technical assistance is designed to assist tho less-developed countries in themselves solving chronic and age-long problems and represents only a fraction of sustained national effort required for appreciable and enduring results. The approved programme for 1954, for example, includes some eight hundred projects in each of which the average number of experts is about two throughout the year, and a hundred and fifteen projects which include only one fellowship each and no experts. Secondly, relatively little equipment is provided with the expert assistance : in 1953 only 10 per cent of obligations was for equipment and only about 6 per cent is planned for 1954 . Thirdly, the Expanded Programme is not related directly to any source of capital supply.

Experience seems to show that a large proportion of the Programme in widely different fields must be devoted to training national personnel in the lessdeveloped countries. Often these training facilities are linked with, or followed by, the award of fellow. ships to candidates recommended by the government concerned to enable thom to follow a specified course at teaching institutions abroad. In many countrios international experts have assisted governments in developing the institutional framework required for experimental work, pilot projects and development. It is also emphasized that the degree of underdevelopment and the requirements of various countries differ widely, and in most fields specific instruction and demonstration as to how to do things are taking the place of general advice as to what needs to be done.
During the year attempts were made for the first: time to work out comprehensive technical assistance? programmes at the country-level, and special attention to the possibilities of economy in the Board's field establishments led to a $\mathbf{2 4 . 5}$ per cent reduction in the estimated costs of these establishments for 1954. The holding of the Pledging Conference before the beginning of the Programme year also eased financial management in 1953, and the approval by the 'Technical Assistance Committee and the Economic and Social Council of proposals for the establishment of a reserve which might be utilized as a working capital and reserve fund should enable the Board to make advances to tide over time-lags between pledges and payment and to satisfy special currency requirements. Financial ceilings are now being imposed on obligations in order to regulate the rate of expenditure in relation to the rate of estimated collection. The Board is also re-examining the criteria and techniques to be used in judging the results of individual projects and the effectiveness of country programmes as a whole. In spite, however, of the improvement in financial management, the determined attack on administrative costs, the stronger co-operation between governments, agencies and the Board's representatives at the country-level and the improved co-ordination with other technical assistance programmes, much remains to be done to improve the operation of the Programme, to make more effective use of limited resources and to come to terms with the dimensions of the task for which the Expanded Programme was created. Once again it is clear that educational and economic: advance should go side by side. Neither should dominate the other. This report should assist in formulating a clear conception of the principles involved in technical aid and what they require; and to overcome the difficulties encountered in obtaining a sufficient supply of experts and retaining their services, it may well prove necessary to form an international cadre with continuous and guaranteed agreed terms of service operating for something in the nature of a World Development Authority.

\section{FISH CULTURE IN INDONESIA}

HERE has recently been published by the Food and Agriculture Organization (F.A.O.) a highly important report* on fish culture in Indonesia. This report comprises a selection of the papers delivered and discussed at a seminar on brackish- and freshwater fish culture, held at Djakarta during April 11May 23, 1951, under the $x$ gis of the Indo-Pacific Fisheries Council.

It is now generally recognized that the fish resources of the sea, vast though they be, are not limitless, nor are they uniformly distributed throughout the seas and oceans of the world. In many highly populated regions of the earth, especially within the tropies, the marine fisheries are as yet poorly developed and their yields make inadequate contributions to the needs of the inhabitants. In consequence, great effort is being made in many such regions-much of it under the inspiration and guidance of the Food and Agriculture Organization-to increase the yield of sea foods.

* Fish Culture in Indonesia. G. Is. Kesteven, General Editor. Indo-Paciflc Fisheries Council (F.A.O.) Special Publication No. 2 . I.P.F.C. Secretariat,
Bangkok, 1953.) n.p. 
This can be done only by streamlining and improving fishing methods and intensifying fishing effort. It is already clear, however, that in many places the ultimate yields from the sea's natural resources can never fully meet the unsatisfied demands for animal proteins; and no means have yet been found of adding appreciably to the sea's productivity by culture methods. Fish farming is not feasible in the sea; but in brackish lagoons and fresh inland waters it is both possible and profitable and has long been practised in various parts of the world.

Great effort to improve and extend the practice of fish culture in fresh and brackish waters is therefore now being made, especially in the Indo-Pacific region. This volume on fish culture in Indonesia is thus a most valuable document. It opens with a general description of the inland fisheries of Indonesia followed by reports on: (1) the anatomy and physiology of the milkfish or bandeng, Chanos chanos; (2) the capture and transportation of its fry for stocking purposes; (3) the breeding of carp, Cyprinus carpio; (4) the plankton populations of brackish-water ponds; (5) the occurrences of Anopheles larvæ in rice fields during combined cultivation of rice and fish. There are also brief notes on many other allied problems.

Practical fish culturists and all others interested in improving and extending the science and art of fish culture will be grateful to the Food and Agriculture Organization for providing in this publication such a rich fund of useful information.

The Organization has also published a second (revised) edition of its valuable List of Scientific and other Periodicals published in the Indo-Pacific Area*.

G. A. Steven

* List of Scientific and other Periodicals published in the IndoPacific Area. 2nd edition (revised). Indo-Pacifle Fisheries Council, East, Bangkok, 1953.) n.p.

\section{PARTICIPATION OF COENZYME A IN THE OXIDATION OF FAT*}

\section{By Prof. F. LYNEN}

Biochemical Department, University Chemical Laboratory,

$\mathrm{R}$ ESEARCH in recent years has greatly increased our understanding of the pathways involved in fat metabolism and has confirmed the classical $\beta$-oxidation theory of Knoop ${ }^{1}$ as the chief process by which fatty acids are oxidized. Fatty acid chains undergoing this process are cleaved into $\mathrm{C}_{2}$-fragments, until recently known as 'active acetate', as their true nature was a mystery. The discovery of coenzyme A by Lipmann ${ }^{2}$ was followed by that of the 'energyrich' acylmercaptans or thioesters ${ }^{3}$. This led to the identification, three years ago, of 'active acetate' as the thioester formed from coenzyme $\mathbf{A}$ and acetic acid (acetyl-coenzyme A) ${ }^{4}$. Knowing this, it was possible to formulate a provisional scheme for the

* Summary of a lecture given on March 8 at University College London. The experimental work reported was aided by grants from the Deutsche Forschungsgemeinschaft, Bad Godesberg, and the Rockefeller Foundation, New York.

\section{$\left(F A D=F A D H_{2}\right)$}

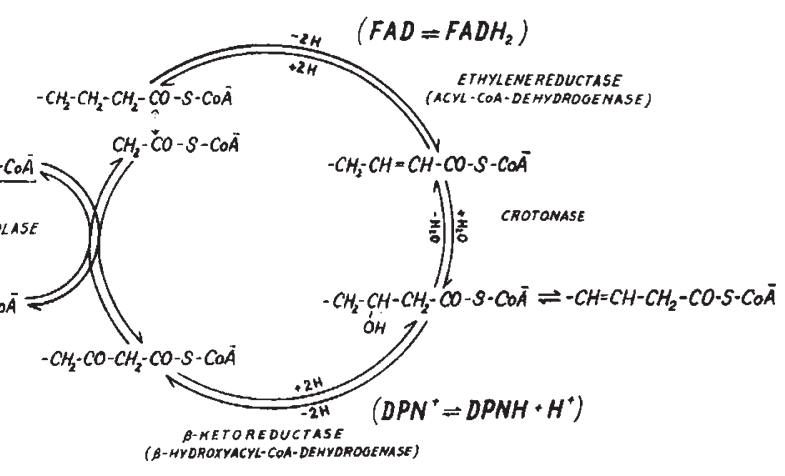

Fig. 1. Fatty acid cycle

oxidation and synthesis of fatty acids ${ }^{4-6}$. The essentials of this scheme were soon confirmed, owing to the rapidity with which the enzyme systems involved were isolated and studied by several laboratories ${ }^{7-10}$, including my own in Munich ${ }^{11}$.

This scheme (Fig. 1) represents a 'fatty acid cycle'. The synthesis of fatty acids is achieved by a repetition of four consecutive steps, catalysed by four new enzymes, which hand to each other substrates of different chain-length. (Recent experiments show that there exist two ketothiolases ${ }^{7}$ and two ethylene reductases ${ }^{8}$, each specific to substrates with certain chain-lengths.) I have named these enzymes according to the direction of their equilibria under physiological conditions. The four steps are as follows: (1) one molecule of acetyl-coenzyme A condenses with another, giving acetoacetyl-coenzyme A ; (2) acetoacetyl-coenzyme $\mathrm{A}$ is reduced to $\beta$-hydroxybutyrylcoenzyme $\mathbf{A}$ in the presence of reduced diphosphopyridine nucleotide ; (3) $\beta$-hydroxybutyryl-coenzyme A undergoes dehydration to crotonyl-coenzyme A; (4) crotonyl-coenzyme A is reduced to butyrylcoenzym' $\mathrm{A}$ in the presence of reduced flavine.

In these four steps the carbon chain of the original acetyl-coenzyme $\mathrm{A}$ is extended by two carbon atoms. An additional acetyl-coenzyme $\mathrm{A}$ and four additional hydrogen atoms are required. The butyryl-coenzyme A so formed can re-enter the cycle through condensation with another molecule of acetyl-coenzyme A to give ketocaproyl-coenzyme $\mathbf{A}$, afterwards undergoing reduction to caproyl-coenzyme $A$. The repetition of the cycle eight times in a spiralwise manner will produce stearyl-coenzyme $\mathbf{A}\left(\mathrm{C}_{18}\right)$. Fatty acid coenzyme A derivatives formed in the 'spiral' can transfer their acyl groups to $\alpha$-glycerophosphate, forming diacyl phosphatidic acids ${ }^{12}$, possible precursors of the phosphatides and true fats. The transferring enzyme concerned is highly specific for fatty acid chains of 16,17 or 18 carbon atoms, which may account for Table 1, $R-\mathrm{CO}-\mathrm{S} \quad \mathrm{CH}_{2}-\mathrm{CH}_{2}-\mathrm{NH}-\mathrm{CO}-\mathrm{Crr}_{3}$

\begin{tabular}{|c|c|c|}
\hline $\operatorname{Acyl}(R-\mathrm{CO})$ & $\begin{array}{c}\text { Melting } \\
\text { point }\end{array}$ & Investigator \\
\hline $\mathrm{CH}_{3}-\mathrm{CO}-$ & $30^{\circ}$ & R. Kuhn and F. Quadbeck \\
\hline $\mathrm{CH}_{3}-\mathrm{CH}_{2}-\mathrm{CH}_{2}-\mathrm{CO}-$ & $28^{\circ}$ & W. Seubert \\
\hline${ }_{\mathrm{OH}}$ & fl. & $\begin{array}{l}\text { T. Wieland and A. Bernhard, } \\
\text { K. Decker }\end{array}$ \\
\hline $\mathrm{SH}_{3}-\underset{\mathrm{H}}{\mathrm{C}}-\mathrm{CH}_{2}-\mathrm{CO}-$ & $60^{\circ}$ & G. Vogelmann and $\mathrm{L}$. Wessely \\
\hline $\begin{array}{l}\mathrm{CH}_{3}-\left(\mathrm{CH}_{2}\right)_{3}-\mathrm{CO}- \\
\mathrm{CH}_{8}-\left(\mathrm{CH}_{2}\right)_{4}-\mathrm{CO}- \\
\mathrm{CH}_{3}-\left(\mathrm{CH}_{2}\right)_{6}-\mathrm{CO}-\end{array}$ & $\begin{array}{c}22^{\circ} \\
45-46^{\circ} \\
60^{\circ}\end{array}$ & $\begin{array}{l}\text { W. Seubert } \\
\text { W. Seubert } \\
\text { W. Seubert }\end{array}$ \\
\hline
\end{tabular}

